\title{
Effect of inbreeding depression on survival of Austrian Brown Swiss calves and heifers
}

\author{
B. Fuerst-Walt| ${ }^{\star 1}$ and C. Fuerst $\dagger$ \\ *University of Natural Resources and Life Sciences, Vienna, Department of Sustainable Agricultural Systems, Division of Livestock Sciences, \\ Gregor Mendel-Str. 33, 1180 Vienna, Austria \\ †ZuchtData EDV-Dienstleistungen GmbH, Dresdner Str. 89/19, 1200 Vienna, Austria
}

\begin{abstract}
The aim of this study was to estimate inbreeding depression for juvenile mortality in Austrian Brown Swiss replacement heifers born in the years 2001 to 2007. After data editing, records of 69,571 animals were investigated. In total, the pedigree consisted of 203,894 animals. Mean and median inbreeding coefficients were 0.0514 and 0.0475 , respectively. The following periods were defined for analyses of juvenile mortality: $\mathrm{P} 1=48$ $\mathrm{h}$ to $30 \mathrm{~d}, \mathrm{P} 2=31$ to $180 \mathrm{~d}, \mathrm{P} 3=181$ to the day before first calving or a maximum age of $1,200 \mathrm{~d}$ if no calving was reported, $\mathrm{P} 4=48 \mathrm{~h}$ to the day before age at first calving or a maximum age of $1,200 \mathrm{~d}$ if no calving was reported. Mortality during the first $30 \mathrm{~d}$ of life was $3.2 \%$; in the total rearing period, $9.3 \%$ of the heifers died (excluding slaughtered and exported animals). For the estimation of the effect of inbreeding and of genetic parameters a linear animal model with the random effects herd-year of birth and animal as well as the fixed effects year of birth-month of birth and dam parity, and the continuous effect of inbreeding coefficient (linear and quadratic) was applied. The model was reduced to the linear effect of inbreeding as the quadratic term was not found to have a significant effect. Inbreeding significantly affected all traits unfavorably. In the full rearing period (P4), heifer calves with an inbreeding coefficient of 0.10 had a $4.9 \%$ higher mortality rate than heifer calves with no inbreeding.
\end{abstract}

Key words: Brown Swiss cattle, inbreeding depression, mortality, heifer

\section{INTRODUCTION}

Apart from stillbirth rate, survival of calves and heifers is among the less frequently studied functional traits

Received July 5, 2011.

Accepted June 3, 2012.

${ }^{1}$ Corresponding author: birgit.fuerst-waltl@boku.ac.at in dairy cattle. Many factors may influence mortality in young breeding stock. Among the most important ones are dystocia, respiratory diseases, and diarrhea; along with those, various environmental and physiological factors (e.g., Svensson et al., 2006; Lombard et al., 2007; Gulliksen et al., 2009) but also genetics (e.g., Fuerst-Waltl and Fuerst, 2010; Fuerst-Waltl and Sørensen, 2010; Henderson et al., 2011) were found to affect survivability. Another internal factor possibly having an effect on calf and heifer mortality is inbreeding. The inbreeding coefficient describes the probability that 2 alleles are identical by descent. The decrease in performance due to inbreeding is known as inbreeding depression (Falconer and Mackay, 1996). Inbreeding depression may be explained by different hypotheses. As reviewed by Wright et al. (2008), the partial dominance theory is generally considered to be the main reason for inbreeding depression but evidence for the overdominance hypothesis also exists. The partial dominance hypothesis reflects the fact that by inbreeding the frequency of homozygotes is increased and, thus, deleterious recessive alleles have a higher probability of being expressed. The overdominance hypothesis is based on the assumption that heterozygotes are superior to either homozygote. Inbreeding thus reduces the proportion of superior heterozygotes. Further, inbreeding depression may be explained by the separation of epistatic interaction between loci (Templeton and Read, 1994). Generally, inbreeding depression is stronger in traits that are closely related to fitness (e.g., survival and fertility) than in other traits (DeRose and Roff, 1999). Inbreeding depression is well documented for many fitness-related traits in plants, animals, and humans (Charlesworth and Willis, 2009) including stillbirth (e.g., Adamec et al., 2006) and longevity (e.g., Sewalem et al., 2006) in dairy cattle. However, to our knowledge, no studies have been published on inbreeding depression for calf and heifer survival in dairy cattle. Hence, the objective of this study was to estimate inbreeding depression on the survival of replacement stock in Austrian Brown Swiss at different ages as well as conducting a genetic analysis for these traits. 


\section{MATERIALS AND METHODS}

\section{Data}

Records of Austrian Brown Swiss calves and heifers born between January 1, 2001, and December 31, 2007, were extracted from the nationwide cattle performance database. Information about survival of calves is available due to the obligatory cattle registration in the European Union [regulation (European Commission, EC) no. 1760/2000] and was obtained for the period between January 1, 2001, and February 10, 2008. Data were further restricted to singleton females, a maximum foreign gene proportion of $12.5 \%$, as well as to animals with full records regarding calving ease, herd, and parentage. Animals slaughtered or exported during their first $30 \mathrm{~d}$ of life were discarded as well as animals that were sold to another farm. Furthermore, records of dams with a length of pregnancy less than 270 or greater than $306 \mathrm{~d}$, and an age at first calving lower than $550 \mathrm{~d}$ or higher than $1,200 \mathrm{~d}$ were excluded in accordance with the routine breeding value estimation procedures. After that, data were restricted to herdyear of birth classes having a minimum of 5 records, and sires having at least 10 daughters.

In accordance to earlier studies in Austrian dualpurpose Fleckvieh (Fuerst-Waltl and Fuerst, 2010) and Danish Holstein (Fuerst-Waltl and Sørensen, 2010), survival was analyzed in different defined periods: $\mathbf{P} \mathbf{1}$ $=48 \mathrm{~h}$ to $30 \mathrm{~d}$ (born dead and died by $48 \mathrm{~h}$ postpartum is defined as stillbirth; Fürst and Fürst-Waltl, 2006), $\mathbf{P 2}=31$ to $180 \mathrm{~d}, \mathbf{P 3}=181 \mathrm{~d}$ to the day before first calving or a maximum age of $1,200 \mathrm{~d}$, and $\mathbf{P} \mathbf{4}=$ from $48 \mathrm{~h}$ to the day before first calving or a maximum age of 1,200 d. Periods P1 and P2 correspond to neonatal and calf mortality as defined by Wathes et al. (2008). According to the suggestion of Fuerst-Waltl and Fuerst (2010), only one period (P3) was defined for heifer mortality. Period P4 corresponds to the full period between birth and first calving, not including the day of calving itself. Thus, losses due to dystocia are not considered for the analysis of heifer mortality. Records of calves and heifers that were slaughtered or exported within a period and those too young to theoretically reach the maximum age of the respective period were set to missing for the period in question or subsequent periods, but their records were kept for preceding periods. The calves and heifers were scored as 1 if they died within the respective period and 0 otherwise.

In total, records of 69,571 calves and heifers of 933 sires were investigated. Pedigree information was also extracted from the national database and was traced back as far as possible to animals born in 1950 or later. The pedigree consisted of 203,894 animals. Data preparation and descriptive statistics were carried out by software package SAS 9.2 (SAS Institute, 2008). Inbreeding coefficients were calculated with the program RelaX2 (Strandén and Vuori, 2006) using a modified algorithm based on the method of Meuwissen and Luo (1992). Using the same software, the complete generation equivalent (Maignel et al., 1996) was calculated to describe the quality of the pedigree. This measure is defined as the sum of the proportion of known ancestors over all generations traced.

\section{Statistical Analysis}

The software package ASReml (Gilmour et al., 2006) was used to estimate the effect of inbreeding on survival traits of calves and heifers. In an earlier genetic analysis of such traits in Austrian Fleckvieh (Fuerst-Waltl and Fuerst, 2010) and Danish Holstein (Fuerst-Waltl and Sørensen, 2010), threshold models accounting for the binary nature of the data were also applied and compared with linear models. In this study, the focus is on linear models as (1) the methodology (linear vs. threshold) was found to have little effect on the results in the above-mentioned studies and (2) the regression coefficients are on an interpretable scale when applying linear models. Thus, all traits were analyzed with univariate linear animal models:

$$
\begin{gathered}
\mathrm{Y}_{\mathrm{ijkl}}=\mu+\mathrm{HY}_{\mathrm{i}}+\mathrm{YM}_{\mathrm{j}}+\text { Parity }_{\mathrm{k}}+\mathrm{b}_{1} \mathrm{~F}+\mathrm{b}_{2} \mathrm{~F}^{2} \\
+\operatorname{animal}_{1}+\varepsilon_{\mathrm{ijkl}},
\end{gathered}
$$

where $\mathrm{Y}_{\mathrm{ijkl}}=$ individual observation of mortality in $\mathrm{P} 1$ to $\mathrm{P} 4, \mu=$ the overall mean, $\mathrm{HY}_{\mathrm{i}}=$ the random effect of herd $\times$ year of birth (herd $=1, \ldots, 154$; year $=2001$, $\ldots, 2007), \mathrm{YM}_{\mathrm{j}}=$ the fixed effect of year of birth $\times$ month of birth j, Parity ${ }_{\mathrm{k}}=$ the fixed effect of the dam's parity $\mathrm{k}(\mathrm{k}=1, \ldots, 5$, with parities $>5$ set to 5$), \mathrm{b}_{1}$ and $b_{2}=$ regression coefficients, $\mathrm{F}=$ the continuous effect of the inbreeding coefficient (linear and quadratic), animal $_{1}=$ the random genetic effect of animal l, and $\varepsilon_{\mathrm{ijkl}}$ $=$ the random residual. Further, 6 genetic groups were defined depending on country of origin.

Heritability was estimated as

$$
h^{2}=\frac{\sigma_{a}^{2}}{\sigma_{a}^{2}+\sigma_{h y}^{2}+\sigma_{e}^{2}},
$$

with $\sigma_{a}^{2}, \sigma_{h y}^{2}$, and $\sigma_{e}^{2}$ being additive genetic, herd-year, and residual variances, respectively. 
Table 1. Completeness of pedigree per generation in percent for studied animals per birth year (year) and across birth years (total)

\begin{tabular}{lccccccccc}
\hline & & \multicolumn{7}{c}{ Completeness per generation (\%) } \\
\cline { 3 - 10 } Year & \multicolumn{1}{c}{$\mathrm{n}$} & 1 & 2 & 3 & 4 & 5 & 6 & 7 & 8 \\
\hline 2001 & 9,063 & 100.0 & 98.7 & 95.9 & 89.7 & 52.8 & 6.1 & 0.0 & 0.0 \\
2002 & 9,664 & 100.0 & 98.6 & 96.4 & 90.3 & 59.2 & 9.3 & 0.0 & 0.0 \\
2003 & 9,389 & 100.0 & 98.7 & 96.8 & 90.2 & 65.0 & 10.7 & 0.1 & 0.0 \\
2004 & 9,498 & 100.0 & 98.7 & 97.1 & 92.1 & 66.0 & 14.0 & 0.0 & 0.0 \\
2005 & 10,335 & 100.0 & 99.0 & 97.3 & 94.0 & 75.0 & 18.8 & 0.3 & 0.0 \\
2006 & 10,982 & 100.0 & 98.8 & 97.5 & 93.7 & 75.7 & 20.5 & 0.1 & 0.0 \\
2007 & 10,640 & 100.0 & 99.2 & 97.7 & 94.0 & 78.3 & 26.4 & 0.3 & 0.0 \\
Total & 69,571 & 100.0 & 98.8 & 97.0 & 92.1 & 68.0 & 15.5 & 0.1 & 0.0 \\
\hline
\end{tabular}

\section{RESULTS}

\section{Descriptive Statistics}

The completeness of pedigree per generation is presented in Table 1. Complete pedigrees were available up to the seventh ancestor generation. The complete generation equivalent across birth years ranged from 9.00 (2001) to 10.07 (2007). In Table 2, the level of inbreeding is shown for the 69,571 Brown Swiss heifer calves under study. Only 511 animals were not inbred at all, 69 individuals had inbreeding coefficients equal to or higher than 0.25 , with the maximum inbreeding coefficient being 0.33 . Mean and median inbreeding coefficients were 0.0514 and 0.0475 , respectively. From the birth years 2001 to 2007, a steady increase of the mean inbreeding coefficient from 0.045 to 0.058 could be observed. Mean inbreeding coefficients for the total population were slightly lower than those of the studied animals (Figure 1).

During the first month of life, the mortality of the analyzed 69,571 Brown Swiss heifer calves was 3.2\% (Table 3). Of all heifer calves dying within P1 in this study, $50 \%$ died within the first $12 \mathrm{~d}$. In later periods P2 and P3, mortality rates were lower. Of the 35,299 heifers theoretically reaching the maximum age of $1,200 \mathrm{~d}$ at the end of the total period between birth and age of first calving (P4), 21.6\% were slaughtered or exported and $7.3 \%$ died; the median age of death was $59 \mathrm{~d}$. When excluding slaughtered and exported

Table 2. Level of inbreeding ( $\mathrm{F}=$ inbreeding coefficient) for the studied heifer calves $(\mathrm{n}=69,571)$

\begin{tabular}{lc}
\hline Inbreeding coefficient & $\begin{array}{c}\text { Proportion of } \\
\text { individuals }(\%)\end{array}$ \\
\hline $\mathrm{F}=0$ & 0.73 \\
$0<\mathrm{F}<0.0625$ & 75.05 \\
$0.0625 \leq \mathrm{F}<0.125$ & 23.09 \\
$0.125 \leq \mathrm{F}<0.1875$ & 0.96 \\
$0.1875 \leq \mathrm{F}<0.25$ & 0.07 \\
$\mathrm{~F} \geq 0.25$ & 0.10 \\
\hline
\end{tabular}

animals, the mortality accounts for 9.3\% in P4. Large phenotypic differences were found for the offspring of different sires. For the 277 bulls with a minimum of 50 recorded heifers in the data set, mortality rates in $\mathrm{P} 1$ ranged from 0 to $10.4 \%$. The corresponding range for the full period $\mathrm{P} 4$ and 113 bulls was 0 to $20 \%$.

\section{Inbreeding Depression}

The results for all effects in the model including the solution for the inbreeding coefficient are shown in Table 4. The model was reduced to the linear effect of inbreeding for all periods under study, as the quadratic term was not found to have a significant effect. In the reduced model, inbreeding significantly affected all traits unfavorably with $P<0.001$ for P1, P2, and $\mathrm{P} 4$ and $P<0.01$ for P3, respectively. For heifers with inbreeding coefficients of 0.10 , the average mortality was $1.8,1.2,1.5$, and $4.9 \%$ higher for P1, P2, P3, and $\mathrm{P} 4$, respectively, than for noninbred heifers. All other effects were highly significant for P1 only; dam parity additionally had a significant effect for P4, whereas a trend could be observed for P2. Generally, mortality of offspring of dams in earlier lactations was higher.

\section{Genetic Parameters}

Estimated variance components and heritabilities are presented in Table 5. Heritabilities for P1, P2, and P3 and the linear animal model were lower than 0.01, ranging from $0.002(\mathrm{P} 3)$ to $0.009(\mathrm{P} 1)$. For P4, a value $( \pm \mathrm{SE})$ of $0.014 \pm 0.005$ was estimated.

\section{DISCUSSION}

The quality of the pedigree is a very important factor when interpreting inbreeding coefficients. With a complete generation equivalent between 9.0 and 10.1 and a completeness of the pedigree for the fourth ancestor generation ranging from 89.7 to $94.0 \%$ (Table 1) for the 
Table 3. Number of observations in total (n); number of animals that died, were culled, or were exported in different periods $(\mathrm{P} 1=2-30 \mathrm{~d}, \mathrm{P} 2=31-180 \mathrm{~d}, \mathrm{P} 3=181 \mathrm{~d}$ to day before first calving or a maximum of 1,200 $\mathrm{d}$, and $\mathrm{P} 4=2 \mathrm{~d}$ to day before first calving or a maximum of 1,200 d); and median age at death

\begin{tabular}{lcccc}
\hline Period & $\mathrm{n}^{1}$ & $\begin{array}{c}\text { Animals slaughtered } \\
\text { or exported }\end{array}$ & Animals died & $\begin{array}{c}\text { Median age at } \\
\text { death (d) }\end{array}$ \\
\hline P1 & 69,571 & $-^{2}$ & 2,200 & 12 \\
P2 & 62,372 & 1,768 & 1,408 & 68 \\
P3 & 32,326 & 6,391 & 842 & 454 \\
P4 & 35,299 & 7,626 & 2,580 & 59 \\
\hline
\end{tabular}

${ }^{1}$ Excluding animals not (theoretically) reaching the maximum age of period.

${ }^{2}$ Due to data editing, 405 animals being exported or slaughtered during the first $30 \mathrm{~d}$ of life were excluded from analysis.

birth years 2001 and 2007, respectively, the depth and quality of the available pedigree may be considered as rather high. The mean inbreeding coefficient of Austrian Brown Swiss in the birth year 2001 was 0.045 and is comparable to that in the American Brown Swiss population (Weigel, 2001). The mean inbreeding coefficients for the studied animals born in the years 2001 to 2007 were almost identical to those for the same birth years in the total population (Figure 1). The rather strong editing process, thus, did not affect the level of inbreeding in this study. Similar to other dairy cattle populations, an increase in inbreeding could be observed during the last centuries (e.g., Sørensen et al., 2005; Sewalem et al., 2006; McParland et al., 2007a).

The mortality of heifers during the first month of life reported in the present study $(3.2 \%)$ was higher than that in Austrian Fleckvieh cattle (1.8\%, FuerstWaltl and Fuerst, 2010), but in accordance to values reported in other countries and breeds (e.g., 3.4 and $3.2 \%$ in British cattle; Brickell et al., 2007) and Danish Holstein cattle (Fuerst-Waltl and Sørensen, 2010), respectively;. In an older study in US Brown Swiss heifer calves (Erf et al., 1990), a mortality of $2.6 \%$ was reported for the first week of life. Differences in the definition of stillbirth, however, have to be taken into account when interpreting early postnatal mortality. Whereas in many countries, stillbirth is defined as being born dead or died within $24 \mathrm{~h}$ after birth, in the joint Austrian-German genetic evaluation, calf mortality up to $48 \mathrm{~h}$ contributes to stillbirth (Fürst and Fürst-Waltl, 2006). Nevertheless, the stillbirth rate of $4.3 \%$, as published in the previously cited investigation for Austrian Brown Swiss in 2005, is lower than in most other dairy cattle populations. For example, in Danish Holstein cattle, a stillbirth rate of $9.5 \%$ for first and $5.4 \%$ for later calvings was reported in the year 2008 (Team Avlsværdivurdering Dansk Kvæg, 2009). Similar stillbirth rates were, for example, shown for Canadian and US Holsteins (Meyer et al., 2001; Van Doormaal and Brand, 2006).

In accordance with studies on Austrian Fleckvieh (Fuerst-Waltl and Fuerst, 2010) and Danish Holstein (Fuerst-Waltl and Sørensen, 2010), more animals died during the first month of life than between 1 and 6 mo. This confirms that also in Brown Swiss, the risk of calf mortality is highest during the early stages of life. In Danish Jersey heifers (Norberg, 2008), mortality was analyzed during the first $180 \mathrm{~d}$ of life. A rather alarming proportion of $12.5 \%$ of all heifer calves died during the first half year after birth.

For the full period until first calving and excluding slaughtered or exported animals from analysis, the mortality of Austrian Brown Swiss heifers (9.3\%) was also higher than that of Austrian Fleckvieh heifers (5.6\%;

Table 4. Levels of significance ( $P$-value) for effects in the model as well as solutions (SE in parentheses) for regression coefficients in different periods $^{1}$

\begin{tabular}{|c|c|c|c|c|}
\hline Effect & $\mathrm{P} 1(\mathrm{n}=69,571)$ & $\mathrm{P} 2\left(\mathrm{n}=60,604^{2}\right)$ & P3 $\left(\mathrm{n}=25,935^{2}\right)$ & $\mathrm{P} 4\left(\mathrm{n}=27,673^{2}\right)$ \\
\hline Year $\times$ month & $<0.001$ & $\mathrm{NS}^{3}$ & NS & NS \\
\hline Dam parity & $<0.001$ & 0.081 & NS & $<0.001$ \\
\hline \multicolumn{5}{|l|}{ Regression coefficient } \\
\hline Inbreeding coefficient - linear & $0.176(0.036)$ & $0.115(0.033)$ & $0.151(0.059)$ & $0.495(0.097)$ \\
\hline
\end{tabular}

${ }^{1}$ Models were reduced to linear regression coefficients, as the quadratic term was not significant for any period. Periods: P1 $=2-30 \mathrm{~d}$, P2 $=$ 31-180 d, P3 = $181 \mathrm{~d}$ to day before first calving or a maximum of 1,200 d, and P4 $=2 \mathrm{~d}$ to day before first calving or a maximum of 1,200 d.

${ }^{2}$ Animals exported or slaughtered were set to missing.

${ }^{3}$ NS: $P>0.10$ 


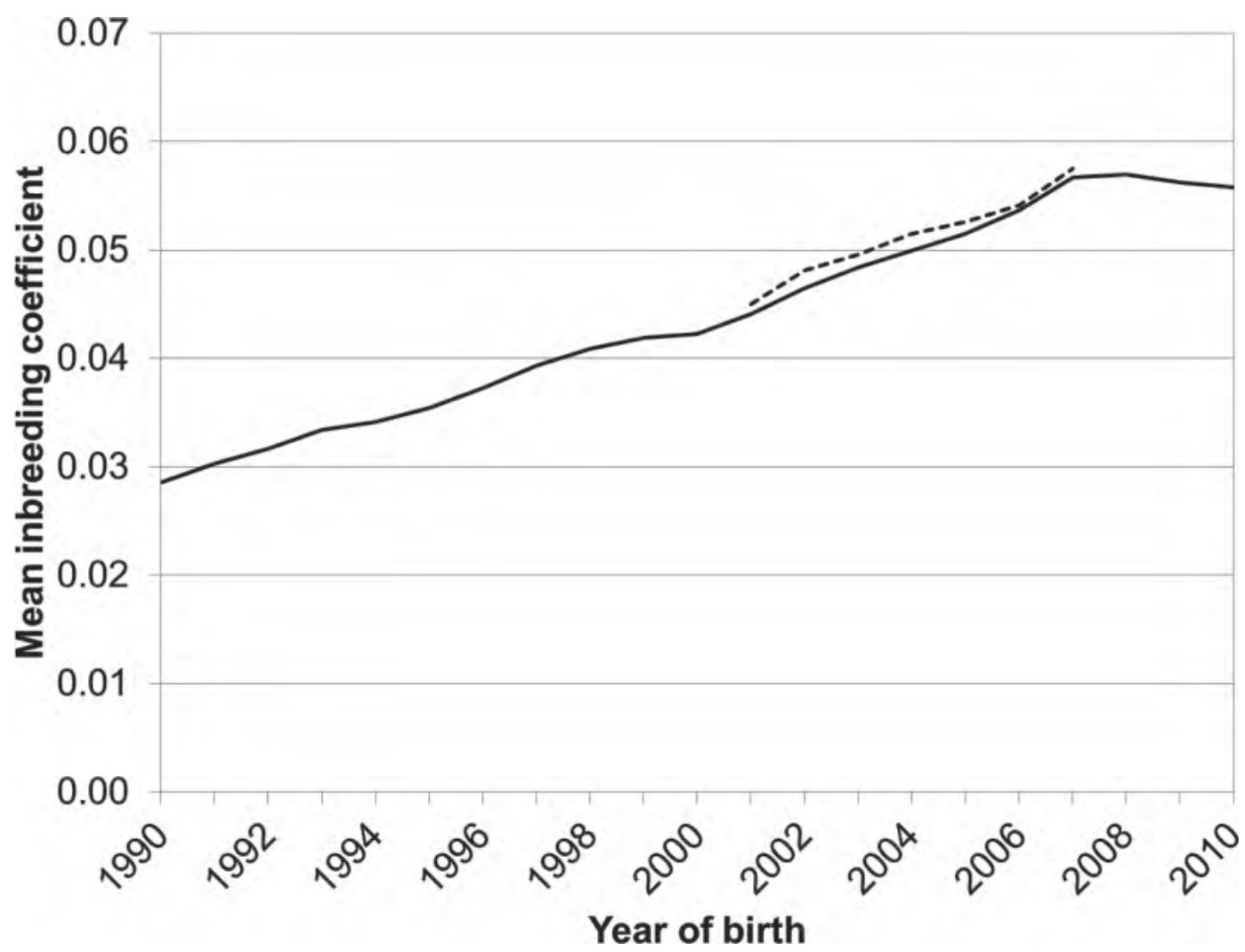
line).

Figure 1. Mean inbreeding coefficient in the Austrian Brown Swiss population (females only, solid line) and in the studied animals (dashed

Fuerst-Waltl and Fuerst, 2010) but comparable with Danish Holsteins (9.4\%; Fuerst-Waltl and Sørensen, 2010). For British dairy farms, Wathes et al. (2008) reported a juvenile mortality rate (i.e., the mortality between 6 mo of age and the start of the service period at about $15 \mathrm{mo}$ ) of $3.5 \%$. However, the authors merged dying and culling events into one single category.

In this analysis, mortality in all stages of replacement heifers' lives was unfavorably affected by inbreeding. Given that overall mortality in the rearing period accounts for $9.3 \%$ (excluding slaughtered and exported heifers), the increase of $0.49 \%$ mortality per $1 \%$ in- breeding may be interpreted as being rather high. Standardized estimates make the extent of inbreeding depression all the more evident. Expressed as percentages of genetic standard deviations, inbreeding depression per $1 \%$ inbreeding is as large as 10.4, 11.5, 22.5, and $14.3 \%$ for P1, P2, P3, and P4, respectively. McParland et al. (2007b) observed considerably lower inbreeding depression for the functional traits age at first calving, calving interval, and survival of cows. For these traits, standardized estimates of inbreeding depression ranged from 1.2 to $1.6 \%$ only. However, with corresponding values of 15.6 to $21.9 \%$ of the additive genetic standard

Table 5. Variance $\left(\sigma^{2}\right)$ components $(a=$ additive genetic, $h y=$ herd-year, $e=$ residual $)$ and heritabilities $\left(h^{2}\right)$ $\pm \mathrm{SE}$ estimated for calf and heifer mortality in different periods

\begin{tabular}{lcccc}
\hline & \multicolumn{3}{c}{ Variance component } \\
\cline { 2 - 4 } Period $^{1}$ & \multicolumn{1}{c}{$\sigma_{a}^{2}$} & $\sigma_{h y}^{2}$ & $\sigma_{e}^{2}$ & $h^{2}$ \\
\hline P1 & 0.0003 & 0.0007 & 0.0295 & $0.009 \pm 0.002$ \\
P2 & 0.0001 & 0.0004 & 0.0222 & $0.005 \pm 0.002$ \\
P3 & $<0.0001$ & 0.0012 & 0.0301 & $0.002 \pm 0.003$ \\
P4 & 0.0012 & 0.0044 & 0.0787 & $0.014 \pm 0.005$ \\
\hline
\end{tabular}

${ }^{1}$ Periods: $\mathrm{P} 1=2-30 \mathrm{~d}, \mathrm{P} 2=31-180 \mathrm{~d}, \mathrm{P} 3=181 \mathrm{~d}$ to day before first calving or a maximum of $1,200 \mathrm{~d}$, and $\mathrm{P} 4=2 \mathrm{~d}$ to day before first calving or a maximum of $1,200 \mathrm{~d}$. 
deviation for milk concentration traits, the authors reported higher inbreeding depression for traits related to milk production. When interpreting the results of inbreeding depression in $\mathrm{P} 2$ and $\mathrm{P} 3$, preselection of data also needs to be considered. Analysis of mortality in these periods is conditional on the calves and heifers surviving the previous periods. In this context, the rather low inbreeding depression for functional traits in the study of McParland et al. (2007b) may also partly be explained. Both, fertility and survival of cows during their first lactation may only be analyzed in animals that conceived as heifers and survived to first calving.

To our knowledge, this is the first study analyzing inbreeding effects on juvenile mortality in dairy cattle. However, in other species, evidence for inbreeding depression on juvenile mortality was found (e.g., Ralls and Ballou, 1982; Köck et al., 2009). In dairy cattle, inbreeding depression was reported for functional traits such as longevity of cows, male and female fertility, dystocia, stillbirth, SCC, and mastitis (e.g., Adamec et al., 2006; Sørensen et al., 2006; Maximini et al., 2011). Regarding the survival of cows, increased inbreeding in Austrian Brown Swiss (Fuerst and Sölkner, 1994) resulted in a decreased length of productive life. On average, the cows' length of productive life was decreased by $4.3 \mathrm{~d}$ per $1 \%$ increase in inbreeding. Similarly, in Canadian Jersey, Holstein, and Ayrshire cows, the relative risk of culling was significantly increased by inbreeding (Sewalem et al., 2006).

Calculated heritabilities were in the range of previously reported values for Austrian Fleckvieh cattle $(<0.01$ to 0.016; Fuerst-Waltl and Fuerst, 2010). Additional results for threshold logit sire models (data not shown) were also in accordance with heritabilities estimated for Austrian Fleckvieh cattle on the underlying scale (Fuerst-Waltl and Fuerst, 2010). In Danish Holstein heifers, slightly higher heritabilities were estimated for mortality in P1, P2, and in the full period (0.017 to 0.042 with a linear sire model; Fuerst-Waltl and Sørensen, 2010). Even though both mortality and involuntary culling contribute to rearing losses, they are most likely affected by different genes. Especially in heifers that have already been inseminated, poor fertility is expected to be among the main reasons for culling. However, disposal codes are not available for heifers. Hence, the categories died and slaughtered were not merged for this analysis. According to an earlier study in Austrian Fleckvieh cattle (Fuerst-Waltl and Fuerst, 2010), additional calculations were carried out for involuntary culling (data not shown). Involuntary culling of heifers was defined as animals that were slaughtered and having at least 1 insemination after $365 \mathrm{~d}$ and before 1,200 d. More than 2,000 animals fell into this category. With heritability $\left(\mathrm{h}^{2}\right)=0.07 \pm 0.01$, the estimated heritability was higher than in Fleckvieh $\left(\mathrm{h}^{2}=0.02\right)$. No significant inbreeding depression was found for this trait, though $(1.4 \%$ more involuntary culling for heifers with an inbreeding coefficient of 0.10 compared with noninbred heifers, $P=0.16$ ).

As suggested by Eaglen et al. (2011), the effects associated with difficult calvings may have long-term consequences on calves. In earlier genetic analyses of heifer mortality in Danish Holstein (Fuerst-Waltl and Sørensen, 2010) and Austrian Fleckvieh (Fuerst-Waltl and Fuerst, 2010) cattle, calving ease was also included in the model as a fixed effect. It was found to affect mortality in the early and full rearing period. However, although the inclusion of calving ease helps to explain mortality, the adjustment for calving ease may bias the genetic and the residual variances downwards (FuerstWaltl and Sørensen, 2010) and also have an effect on the estimate of inbreeding depression. In additional analyses (data not shown), the models were also run including calving ease as a fixed effect. In Austrian Brown Swiss, more difficult calvings significantly affected the mortality in P1 only; the estimates for heritability and inbreeding depression were almost identical when applying both models, with and without calving ease as fixed effect.

As calf and heifer mortality are economically very important traits in dairy cattle breeding (e.g., Østerås et al., 2007), they should be considered in breeding programs. Genetically improving calf and heifer mortality is feasible if genetic and phenotypic variations are reasonably high even if it is a so-called low-heritability trait. The value of potential additional information from a genetic evaluation for survival in the rearing period will also depend on the economic values for the traits. A similar functional trait, stillbirth, is being routinely evaluated in most developed countries. Even though in the case of stillbirth, 2 animals (the dam and the calf) are affected, it is likely that the economic value for mortality of heifers in the rearing period is higher than that for stillbirth. Given that the economic value in the total merit index is reasonably high, genetic gain may be achieved or at least a deterioration of the trait may be avoided. In future breeding program scenarios, genomic selection may also provide a chance for genetic progress in lowly heritable functional traits.

\section{CONCLUSIONS}

Inbreeding significantly affects juvenile mortality in Austrian Brown Swiss cattle and, thus, adds to a large number of functional traits in dairy cattle for which inbreeding depression has been reported. Apart from ethical issues concerning animal health and welfare, higher female calf or heifer mortality has negative ef- 
fects on dairy farmers' profitability due to higher rearing costs and reduced possibility for selection. Both the genetic improvement of this trait and keeping inbreeding as low as possible are, thus, desirable. A mating planner for all cattle breeders with internet access was recently provided by the Federation of Austrian Cattle Breeders (Rinderzucht Austria, 2012). By means of this online application, the expected inbreeding of a potential offspring is calculated and, thus, close inbreeding can be easily avoided.

\section{ACKNOWLEDGMENTS}

Financial support of Birgit Fuerst-Waltl by the Austrian Science Fund (FWF, Vienna, Austria; EliseRichter Program V43-B12) is gratefully acknowledged.

\section{REFERENCES}

Adamec, V., B. G. Cassell, E. P. Smith, and R. E. Pearson. 2006. Effects of inbreeding in the dam on dystocia and stillbirths in US Holsteins. J. Dairy Sci. 89:307-314.

Brickell, J. S., N. Bourne, and D. C. Wathes. 2007. The incidence of calf mortality on dairy farms in southern England. Page 107 in Proceedings of the British Society of Animal Science 2007. Accessed July 5, 2011. http://www.bsas.org.uk/downloads/annlproc/Pdf2007/pdf2007.pdf.

Charlesworth, D., and J. H. Willis. 2009. The genetics of inbreeding depression. Nat. Rev. Genet. 10:783-796.

DeRose, M. A., and D. A. Roff. 1999. A comparison of inbreeding depression in life-history and morphological traits in animals. Evolution 53:1288-1292.

Eaglen, S. A. E., M. P. Coffey, J. A. Woolliams, R. Mrode, and E. Wall. 2011. Phenotypic effects of calving ease on the subsequent fertility and milk production of dam and calf in UK HolsteinFriesian heifers. J. Dairy Sci. 94:5413-5423.

Erf, D. F., L. B. Hansen, and R. R. Neitzel. 1990. Inheritance of calf mortality for Brown Swiss cattle. J. Dairy Sci. 73:1130-1134.

Falconer, D. S., and T. F. C. Mackay. 1996. Introduction to quantitative genetics. 4th ed. Longman, Harlow, UK.

Fuerst, C., and J. Sölkner. 1994. Additive and nonadditive genetic variances for milk yield, fertility, and lifetime performance traits of dairy cattle. J. Dairy Sci. 77:1114-1125.

Fuerst-Waltl, B., and C. Fuerst. 2010. Mortality in Austrian dual purpose Fleckvieh calves and heifers. Livest. Sci. 132:80-86.

Fuerst-Waltl, B., and M. K. Sørensen. 2010. Genetic analysis of calf and heifer losses in Danish Holstein. J. Dairy Sci. 93:5436-5442.

Fürst, C., and B. Fürst-Waltl. 2006. Züchterische Aspekte zu Kalbeverlauf, Totgeburtenrate und Nutzungsdauer in der Milchviehzucht. Züchtungskunde 78:365-383.

Gilmour, A. R., B. J. Gogel, B. R. Cullis, and R. Thompson. 2006. ASReml User Guide. Release 2.0. VSN International Ltd., Hemel Hempstead, UK.

Gulliksen, S. M., K. I. Lie, T. Løken, and O. Østerås. 2009. Calf mortality in Norwegian dairy herds. J. Dairy Sci. 92:2782-2795.

Henderson, L., F. Miglior, A. Sewalem, D. Kelton, A. Robinson, and K. E. Leslie. 2011. Estimation of genetic parameters for measures of calf survival in a population of Holstein heifer calves from a heifer-raising facility in New York State. J. Dairy Sci. 94:461-470.

Köck, A., B. Fürst-Waltl, and R. Baumung. 2009. Effects of inbreeding on number of piglets born total, born alive and weaned in Austrian Large White and Landrace pigs. Arch. Tierz. 52:51-64.
Lombard, J. E., F. B. Garry, S. M. Tomlinson, and L. P. Garber. 2007. Impacts of dystocia on health and survival of dairy calves. J. Dairy Sci. 90:1751-1760.

Maignel, L., D. Boichard, and E. Verrier. 1996. Genetic variability of French dairy breeds estimated from pedigree information. Interbull Bull. 14:49-54.

Maximini, L., B. Fuerst-Waltl, B. Gredler, and R. Baumung. 2011. Inbreeding depression on semen quality in Austrian dual-purpose Simmental bulls. Reprod. Domest. Anim. 46:e102-e104. http:// dx.doi.org/10.1111/j.1439-0531.2010.01645.x.

Mc Parland, S., J. F. Kearney, M. Rath, and D. P. Berry. 2007a. Inbreeding trends and pedigree analysis of Irish dairy and beef cattle populations. J. Anim. Sci. 85:322-331.

Mc Parland, S., J. F. Kearney, M. Rath, and D. P. Berry. 2007b. Inbreeding effects on milk production, calving performance, fertility, and conformation in Irish Holstein-Friesians. J. Dairy Sci. 90:4411-4419

Meuwissen, T. H. E., and Z. Luo. 1992. Computing inbreeding coefficients in large populations. Genet. Sel. Evol. 24:305-313.

Meyer, C. L., P. J. Berger, K. J. Koehler, J. R. Thompson, and C. G. Sattler. 2001. Phenotypic trends in incidence of stillbirth for Holsteins in the United States. J. Dairy Sci. 84:515-523.

Norberg, E. 2008. A genetic study of postnatal mortality in Danish Jersey heifer calves. Page 117 in Book of Abstracts of the 59th Annual Meeting of the European Association for Animal Production, Vilnius, Lithuania. Accessed Jan. 4, 2012. http://www.wageningenacademic.com/_clientFiles/download/Eaap2008-e.pdf.

Østerås, O., M. S. Gjestvang, S. Vatn, and L. Sølverød. 2007. Perinatal death in production animals in the Nordic countries-Incidence and costs. Acta Vet. Scand. 49(Suppl. 1):S14.

Ralls, K., and J. Ballou. 1982. Effect of inbreeding on juvenile mortality in some small mammal species. Lab. Anim. 16:159-166.

Rinderzucht Austria. 2012. Optibull. Handbuch zum Anpaarungsplaner. Accessed July 6, 2012. http://www.zar.at/filemanager/down$\operatorname{load} / 23316 /$.

SAS Institute. 2008. SAS 9.2. SAS Institute Inc., Cary, NC.

Sewalem, A., G. J. Kistemaker, F. Miglior, and B. J. Van Doormaal. 2006. Analysis of Inbreeding and its relationship with functional longevity in Canadian dairy cattle. J. Dairy Sci. 89:2210-2216.

Sørensen, A. C., P. Madsen, M. K. Sørensen, and P. Berg. 2006. Udder health shows inbreeding depression in Danish Holsteins. J. Dairy Sci. 89:4077-4082

Sørensen, A. C., M. K. Sørensen, and P. Berg. 2005. Inbreeding in Danish dairy cattle breeds. J. Dairy Sci. 88:1865-1872.

Strandén, I., and K. Vuori. 2006. RelaX2: Pedigree analysis program. Page 4 in Proc. 8th World Congr. Genet. Appl. Livest. Prod., Belo Horizonte, Brazil. Abstract and CD-ROM.

Svensson, C., A. Linder, and S. O. Olsson. 2006. Mortality in Swedish dairy calves and replacement heifers. J. Dairy Sci. 89:4769-4777.

Team Avlsværdivurdering Dansk Kvæg. 2009. Årsstatistik Avl 2008 09. Accessed Jan. 4, 2012. http://www.landbrugsinfo.dk/Kvaeg/ Avl/Avlsanalyser/Sider/aarsstat2009.pdf.

Templeton, A. R., and B. Read. 1994. Inbreeding: one word, several meanings, much confusion. Pages 91-105 in Conservation Genetics. V. Loeschke, J. Tomiuk, and S. K. Jain, ed. Birkhäuser Verlag, Basel, Switzerland.

Van Doormaal, B., and P. Brand. 2006. Analysis of stillbirth rates (direct and maternal) in Canadian Holsteins. Accessed Jan. 4, 2012 http://www.cdn.ca/Articles/GEBSEPT2006/Analysis_of_Stillbirth_Rates.pdf.

Wathes, D. C., J. S. Brickell, N. E. Bourne, A. Swali, and Z. Cheng. 2008. Factors influencing heifer survival and fertility in commercial dairy farms. Animal 2:1135-1143.

Weigel, K. 2001. Controlling inbreeding in modern breeding programs. J. Dairy Sci. 84(E. Suppl.):E177-E184.

Wright, L. I., T. Tregenza, and D. J. Hosken. 2008. Inbreeding, inbreeding depression and extinction. Conserv. Genet. 9:833-843. 